\title{
Filmes de família: a intimidade representada
}

\author{
Ana Clara Campos dos Santos ${ }^{1}$ \\ Christina Musse ${ }^{2}$
}

\begin{abstract}
Resumo: No presente trabalho, tentamos entender de que forma representamos a nós mesmos diante das câmeras e por quais motivos agimos de determinada maneira quando somos filmados ou fotografados. Este artigo é parte de uma investigação que visa estudar a "direção", a "encenação" e a recepção dos filmes de família. Neste recorte, vamos trilhar um caminho pelos estudos sobre memória, documento e representação. Utilizaremos autores como Andreas Huyssen, no campo da memória, André Bazin, na questão do documento, e Jean-Louis Comolli, falando de representação. Neste artigo consta análise preliminar de filmes de família feitos na década de 1970, na cidade de Juiz de Fora (MG).
\end{abstract}

Palavras-chave: audiovisual; filmes domésticos; representação; identidade; intimidade.

\begin{abstract}
On this essay, we try to understand how we represent ourselves in front of the cameras and why we act on certain ways when we are filmed or photographed. This paper is part of a master's research which will study the "direction", the "acting" and the reception of home movies. In this work, we will trail a way over the studies about memory, document and representation. We will use authors like Andreas Huyssen, in the field of memory, André Bazin, in the question of documents, and Jean-Louis Comolli, speaking about representation. On this essay we make a previous analysis of home movies made on 1970's, at Juiz de Fora (MG).
\end{abstract}

Keywords: audiovisual; home movies; representation; identity; intimacy.

\section{Introdução}

Neste trabalho, discorremos sobre a relação entre memória, documento e representação nos filmes de família. Tentaremos descobrir de que forma a vida privada é representada por seus integrantes e por que temos necessidade de registrar momentos e exibi-los aos outros. Usaremos autores que nos ajudam a trilhar esse caminho como Andreas Huyssen (memória), André Bazin (documento) e Jean-Louis Comolli (representação). Este artigo é um recorte da pesquisa de mestrado sobre

\footnotetext{
${ }^{1}$ Mestranda em Comunicação pela Universidade Federal de Juiz de Fora e integrante do grupo de pesquisa Comunicação, Cidade e Memória (ComCiMe). E-mail: anaclaracs91@gmail.com.

${ }^{2}$ Professora associada do Programa de Pós-Graduação em Comunicação da Universidade Federal de Juiz de Fora. Líder do Grupo de Pesquisa/CNPq Comunicação, Cidade e Memória (ComCiMe). E-mail: musse@terra.com.br
} 
filmes de família, iniciado em 2015. Vamos analisar as representações da vida privada nos filmes de família da década de 1970, em Juiz de Fora, Minas Gerais.

Para introduzir o assunto, falaremos brevemente sobre o surgimento e a popularização do cinema amador. O registro da imagem em movimento foi desenvolvido em 1895, na França, pelos irmãos Louis e Auguste Lumière, que inventaram o cinematógrafo. O cinema tornou-se atraente para as famílias como forma de registro. O mercado volta-se para o público amador e começa a comercializar formatos mais acessíveis do que a bitola de $35 \mathrm{~mm}$, a partir da década de 1920. Em 1923, a Kodak lança a câmera Cine Kodak e o projetor Kodaskope, de bitola16mm; em 1932, lança o Cine Kodak Eight, de 8mm, e o Super 8 (versão mais aprimorada do 8mm), em 1965.

Em 1976, a Japan Video Company (JVC) lança o formato VHS (Vídeo Home System, ou Sistema Doméstico de Vídeo). As diferenças principais entre a película e a fita magnética são, de acordo com Lígia Azevedo Diogo (2010): facilidade operacional, baixo custo, imagem e som simultâneos. Neste ponto, a autora ressalta o vídeo como essencial na história do audiovisual, pois, segundo ela, nenhum outro formato, nem mesmo o Super 8 (que chegou a ter películas com banda sonora), “[...] proporcionava a simultaneidade e a imediaticidade dessa união como no caso do vídeo" (DIOGO, 2010, p.111). Outros pontos de vantagem do vídeo são a possibilidade de monitoramento direto do material gravado, a facilidade de exibição e de copiagem, que atingiu um público grande e variado; diferentemente das películas, que só eram acessíveis para determinadas camadas da população, como defende a autora.

A partir dos anos 2000, no Brasil, pudemos observar a popularização das câmeras digitais. Como toda nova tecnologia, a introdução destas, no início, era alcançada somente pelas elites e por famílias de classe média alta. Na contemporaneidade, pelo fato de as câmeras digitais terem se tornado uma tecnologia amplamente acessível, verificamos certa necessidade das pessoas em registrar momentos fugazes e, muitas vezes, aparentemente sem grande relevância. Mas nossos álbuns particulares são, agora, as redes sociais - lá, colocamos à vista apenas as fotos nas quais parecemos mais bonitos, inteligentes, felizes. Selecionamos as fotos e vídeos que queremos para passar certo tipo de imagem, a imagem que queremos 
que os outros tenham de nós mesmos. Mas em uma escala bem maior do que nos álbuns de família físicos.

\section{Obsessão pela memória}

A questão da memória é extremamente atual, principalmente se levarmos em conta as entrevistas com pessoas que sofreram situações aterrorizantes durante guerras, regimes ditatoriais ou por fazer parte de uma minoria. Esse é o caso de livros sobre o Holocausto judeu, sobre os regimes militares na América Latina e até no caso do genocídio praticado na Colônia, hospício da cidade mineira de Barbacena3. O crítico de arte alemão Andreas Huyssen (2004) afirma: "Um dos fenômenos culturais e políticos mais surpreendentes dos anos recentes é a emergência da memória como uma das preocupações culturais e políticas centrais das sociedades ocidentais.” (HUYSSEN, 2004, p.9).

Na esfera cultural, a memória também é considerada relevante, seja por meio da aquisição de objetos vintage, que remetem a um estilo estético passado ou a alguma época mais feliz e nostálgica da vida, seja pela necessidade de fazer registros de si mesmo. Podemos dizer que esse desejo de memória parece uma forma que as pessoas têm de se diferenciarem, de se tornarem exclusivas. Fazer um vídeo engraçado, que se torna viral na internet, é também uma maneira de uma pessoa protagonizando uma cena embaraçosa - se tornar única, ter seus 15 minutos de fama em algum programa de televisão e ganhar notabilidade. Huyssen ressalta:

Desde a década de 1970, pode-se observar, na Europa e nos Estados Unidos [...] o boom das modas retrô e dos utensílios reprô, a comercialização em massa da nostalgia, a obsessiva automusealização através da câmera de vídeo, a literatura memorialística e confessional, o crescimento de romances autobiográficos e históricos pós-modernos [...]. (HUYSSEN, 2004, p.14)

Quando pensamos nas memórias preservadas em filmes, fotografias, cartas, recortes de jornais, diários, etc., compreendemos serem arquivos que o ser humano produz ou coleta para recordar-se de fatos e eventos específicos ou até mesmo de sentimentos e das relações familiares, entre amigos, entre colegas de trabalho, bem

3 O livro da jornalista Daniela Arbex, Holocausto Brasileiro, mostra esse caso. Pelo menos 60 mil pessoas morreram entre os muros da Colônia. Cerca de 70\% não possuíam nem mesmo diagnóstico de doença mental; eram indesejados sociais: alcoólatras, homossexuais, prostitutas, ou pessoas que se tornaram incômodas para alguém com mais poder. 
como para ressignificar seu próprio papel em determinado grupo, como forma de manter laços identitários. Também podemos pensar na identidade individual: ter acesso aos registros, depois de alguns anos, pode nos fazer refletir sobre quem somos e quem gostaríamos de ser, o que fizemos e o que não fizemos, nossos sucessos e fracassos, nossas escolhas.

Na visão das pesquisadoras Christina e Mariana Musse (2014), o desejo de memória e a grande produção atual de registros são alavancados pela efemeridade dos momentos vividos e pela necessidade de torná-los duradouros, dando maior sentido a nossa existência.

Parece que o registro garante lastro à existência, ressignifica-a, isto é, constrói uma narrativa que, de alguma forma, gera uma identidade. Assim, fotografias, filmes, fitas magnéticas, cds e dvds são suportes capazes de revelar hábitos culturais, subjetividades e maneiras de organizar o mundo ao redor. São uma forma de expressão, mas, além disso, uma forma de memória. (MUSSE; MUSSE, 2014, p.5)

Além de serem motivados pela fugacidade dos momentos, vemos que esses registros são documentos, retratos, não só de memórias individuais, mas também coletivas e características da sociedade de determinada época. Esses artefatos que produzimos são uma forma de preservar nossa própria identidade e nossas particularidades em um mundo tão globalizado e padronizado.

O desejo de memória é analisado também como uma reação à sociedade contemporânea, que, ao privilegiar a instantaneidade, a velocidade e a fluidez, desterritorializa o ser humano, que tentaria, através do passado, conseguir algum tipo de reconhecimento e identificação. (MUSSE; MUSSE, 2014, p.7)

Podemos tentar compreender, dessa forma, do que se trata a obsessão contemporânea pela criação e pelo armazenamento de arquivos que nos proporcionam lembranças de acontecimentos e eventos de nossas vidas. O presente deve ser registrado porque algum dia se tornará passado, principalmente no período em que vivemos, no aqui e agora, com a passagem do passado para o presente sendo cada vez mais rápida, o que pode influenciar na necessidade de registro imediato dos momentos.

Muitos estudiosos de memória ressaltam a característica da identidade em 
seus trabalhos. Principalmente em narrativas orais, a memória é geralmente guiada por lembranças que reforçam quais são os grupos com os quais uma pessoa se identifica. Na psicanálise, a memória é vista como um processo de seleção mental, consciente ou inconsciente, daquilo que lembramos ou do que esquecemos. Essa triagem acontece devido a um fator principal, segundo a psicanalista Jô Gondar (2000): o orgulho.

Orgulho... Se é este o motor do esquecimento, no plano do Estado, da sociedade ou do "eu", o que está em jogo é a manutenção de uma imagem ou representação de si mesmo - vamos chamá-la por seu nome: identidade - e a segregação ou exclusão do que a ameaça: a diferença (GONDAR, 2000, p.37).

Guiados pelo sentimento de orgulho, somos impelidos a guardar mnemonicamente, ou até mesmo a arquivar, momentos da vida dos quais gostamos de falar. Isso ocorre devido ao que consideramos reforçar nossa identidade, o que fortalece a imagem que pretendemos vincular a nós mesmos. Aquilo que não queremos, apagamos, esquecemos, não mostramos (ou revelamos) jamais.

\section{Os documentos que nos mantêm vivos}

O que nos leva a querer arquivar nossas próprias vidas? O historiador Philippe Artières (1998) sugere uma reflexão: de acordo com ele, quando fazemos registros de nossas vidas, pensamos em um futuro leitor ou espectador, através do qual essa prática íntima pode vir a se tornar pública. $\mathrm{O}$ autor chama a atenção para um ponto: não arquivamos nossas vidas sem antes ponderar o que deve ou não ser lembrado. Selecionamos a vida como nos diários pessoais: “[...] omitimos, rasuramos, riscamos, sublinhamos, damos destaque a certas passagens" (ARTIÈRES, 1998, p.11).

O historiador também discorre sobre os álbuns de família - hábito que já foi mais praticado na era analógica, mas atualmente não é tão popular, já que temos a opção de fazer diversos álbuns digitalizados com temas diferentes e muitas fotos em cada um. Porém, podemos comparar esse álbum físico aos álbuns que fazemos nas redes sociais. Geralmente a seleção das fotos, segundo Artières, costumava ocorrer desta forma:

Não colamos qualquer foto nos nossos álbuns. Escolhemos as mais bonitas ou aquelas que julgamos mais significativas; jogamos fora aquelas em que alguém está fazendo careta, ou em que aparece uma figura anônima [...]. 
Acontece, também, com o tempo, de algumas fotos serem retiradas, porque são comprometedoras, porque não são condizentes com a imagem que queremos dar de nós mesmos e da nossa família. (ARTIÈRES, 1998, p.14)

Philippe Artières, então, reforça nossa ideia de que não é necessário "ser" alguma coisa e, sim, "aparentar ser" essa coisa. Convencionalmente, estamos propensos a selecionar a imagem que queremos passar de nós mesmos.

A visão do pesquisador Armando Silva (2008) traz uma questão para refletirmos: acreditamos que o principal motivo para criarmos registros de memória é o medo do esquecimento e o desejo de deixarmos um legado para as gerações futuras. Isso tem relação direta com o que Silva defende, pois, para ele, criamos arquivos por medo da destruição e da morte. De acordo com ele, ao mesmo tempo em que um álbum conta a história de nossas vidas, exibindo momentos felizes, engraçados e belos, compartilhados em família, “o medo da morte é o que o configura [o álbum] como arquivo" (SILVA, 2008, p.50), sendo essa a sua razão de existir.

Contemplar a foto de uma pessoa querida que faleceu traz à tona as lembranças de momentos alegres ao lado dela, mantendo tal pessoa ainda presente em nossas vidas e viva em nossos dias. Porém, uma característica mais ou menos negativa suscitada pela fotografia, que podemos considerar, é o sentimento de saudosismo. Ao mesmo tempo em que podemos sorrir, por lembrarmo-nos dos momentos ao lado da pessoa, podemos também sentir a dor por aquela ausência (principalmente quando é recente), certo arrependimento por não ter aproveitado tanto como poderíamos os momentos ao lado dela, ou a estranha saudade que sentimos das pessoas queridas pela família com quem não chegamos a conviver tanto quanto gostaríamos.

Os registros de família também são uma forma de relíquia, uma herança a ser deixada para as gerações posteriores. Dessa forma, os jovens podem compreender aquelas histórias que não presenciaram, contadas a partir de um álbum ou da projeção de slides e filmes, ressignificando essas narrativas como parte de suas próprias histórias.

O crítico e teórico de cinema André Bazin (1991) possui uma visão da fotografia como uma forma de preservação do corpo, da maneira que foram o 
embalsamamento no Egito antigo, as estátuas e as pinturas que retratavam pessoas. Segundo ele, a fotografia teria o poder de salvar nossos corpos de uma segunda morte, a espiritual, por meio da memória, quase uma mumificação moderna.

Não se acredita mais na identidade ontológica de modelo e retrato, porém se admite que este nos ajuda a recordar aquele e, portanto, a salvá-lo de uma segunda morte espiritual. A fabricação da imagem chegou mesmo a se libertar de qualquer utilitarismo antropocêntrico. O que conta não é mais a sobrevivência do homem e sim, em escala mais ampla, a criação de um universo ideal à imagem do real, dotado de destino temporal autônomo (BAZIN, 1991, p.20).

Em nosso entendimento, essa passagem mostra a visão do autor de que, para as pessoas, não é mais tão importante prolongar a vida real; o mais importante é manter indícios que remetam a nossa imagem pessoal para que esta sobreviva mais do que nós mesmos no tempo.

\section{A representação de si}

Cada gesto que fazemos diante de uma câmera é, geralmente, pensado na forma de encenação própria de cada pessoa. Todos nós atuamos de alguma maneira, agimos conforme o olhar do outro e o olhar da câmera. De acordo com o cineasta e crítico de cinema Jean-Louis Comolli (2001):

Há em todo mundo um saber inconsciente do olhar do outro, um saber que se manifesta por uma tomada de posição, de postura. A cinematografia fornece a prova disso - por um lado porque suscita e solicita essa postura, e por outro porque a registra, perpetuando sua marca [...] Por um saber inconsciente mas certeiro, o sujeito sabe que ser filmado significa se expor ao outro (COMOLLI, 2001, p.109).

Porém, o cineasta coloca que nossa "atuação" sob outros olhares não se trata somente de como nos portamos em frente a uma câmera, mas também da imagem que passamos no dia a dia, nos diferentes campos sociais: o político pai de família, a mãe empresária de sucesso, os avós "corujas", o aluno mais estudioso da sala... JeanLouis Comolli observa:

A auto-mise en scène seria a combinação de dois movimentos. Um, que vem do habitus e que passa pelo corpo (o inconsciente) do agente como representante de um ou de vários campos sociais. $\mathrm{O}$ outro, que tem a ver com o fato de que o sujeito filmado, o sujeito em vista do filme [...] se destina ao filme, consciente $e$ inconscientemente se impregna dele, se ajusta à operação de cinematografia, nela coloca em jogo sua própria mise en scène, no sentido de colocação do corpo no espaço e no tempo definidos pelo olhar do outro (a cena) (COMOLLI, 2001, p.115, grifos do autor). 
Dessa forma, inclusive quando estamos sozinhos interpretamos os papéis sociais que nos são particulares, o tempo todo. Em frente a uma câmera cinematográfica ou de vídeo, devemos nos portar da forma que queremos aparecer para os futuros espectadores.

Os pesquisadores Lígia Diogo e Álvaro Furloni (2009) trilham um breve caminho entre as poses encenadas pelo ser humano, a partir do momento em que este começa a ser retratado fielmente pela fotografia e cinematografia. Eles dividem os tipos de poses em quatro categorias: 1) Pose de estátua - imagem fixa, personagem mascarado; 2) Pose emotiva - imagem fixa, personagem sentimental; 3) Pose forçada - imagem em movimento, personagem congelado ou falante; 4) Pose natural imagem fixa ou em movimento, personagem livre. $\mathrm{O}$ mais interessante para nós, neste trabalho, é falar das imagens em movimento, devido ao objeto de pesquisa desenvolvido: o filme de família. Por isso, vamos utilizar, aqui, as ideias da pose forçada e da pose natural.

No item que descreve a "pose forçada", os autores ainda distinguem os vídeos contratados de eventos familiares e os vídeos feitos por membros da família em eventos familiares. Outra pesquisadora que também observa essas diferenças é Lila Silva Foster (2010), em sua dissertação de mestrado sobre filmes domésticos. Ela diferencia aqueles que são produzidos por cinegrafistas profissionais que filmam a própria família. Podemos dividir o modo de agir da família nos filmes em três categorias:

- Filme de família amador (feito por integrante da família): Nesses filmes, as relações entre cinegrafista e retratados são pessoais, devido à "relação muito próxima da câmera com os retratados e [ao fato de que] são produzidos para o consumo familiar" (FOSTER, 2010, p. 32). Segundo Diogo e Furloni, esse tipo de filme mostra pessoas com poses forçadas, pois "quando conhecem o cinegrafista, são incitadas a dialogar com a câmera ou mandar recados para outros membros da família de maneira 'pouco natural'." (DIOGO; FURLONI, 2009, p.11). Esse filme é caracterizado como amador devido à ausência de técnica.

- Filme de família profissional: Tanto Foster (2010) quanto Diogo e Furloni (2009) concordam que os filmes e vídeos de família feitos por profissionais 
contratados são caracterizados por impessoalidade e distanciamento dos cinegrafistas em relação aos membros da família e os momentos registrados. Os filmes possuem qualidade técnica, mas não apresentam a intimidade específica dos filmes de família.

- Cinegrafista profissional que filma sua própria família: Foster (2010) afirma que, nesse caso, os filmes têm qualidade técnica, mas o fator intimidade familiar não se perde, pois o cinegrafista e os retratados possuem relações de proximidade.

Entretanto, à medida que a tecnologia avança e se populariza, nossas poses tendem a mudar, de acordo com a época. É o que defendem os pesquisadores Lígia Diogo e Álvaro Furloni (2009). Isso se deve ao fato de as tecnologias terem se tornado mais democráticas, o que faz com que as pessoas lidem com as câmeras com muito mais naturalidade do que em outros tempos. Ainda segundo os autores: "poderíamos sugerir que há uma razão proporcional entre o grau de intimidade que se tem com a tecnologia e o grau de intimidade que é captado pela imagem" (DIOGO; FURLONI, 2009, p.7). O que se encontra nas fotos e vídeos de família atuais é a "pose natural" ou ausência de pose, já que o retratado pode não saber que está sendo "clicado", ou não se preocupa mais com isso:

É como se, nesses registros, o olhar, os gestos, o modo de andar e a própria voz de cada pessoa revelassem, de acordo com o grau de intimidade do momento flagrado, por debaixo das máscaras dos personagens $(\mathrm{O}$ Pai, $\mathrm{O}$ Irmão mais Velho, a Princesinha, etc.), os nossos entes queridos, pessoas reais, tão conhecidas e amadas (DIOGO; FURLONI, 2009, p.11).

Mas os autores ainda sugerem que a informalidade e a espontaneidade registradas pelas câmeras não são indício de que estamos livres para agirmos como quisermos, mas, sim, que a preocupação com a imagem de nós mesmos está o tempo todo imbricada em nossos modos de agir no dia a dia. De certa forma, a ideia de Lígia Diogo e Álvaro Furloni de que, na pose natural, deixamos de representar papéis e agimos como se estivéssemos posando o tempo todo dialoga com o conceito de automise en scène de Jean-Louis Comolli (2001), de que representamos sempre os nossos habitus sociais.

Talvez estejamos caminhando para uma auto-mise en scène menos afetada pela "celebrização" dos momentos em família, já que muitos registros são feitos em 
situações rotineiras. Mas acreditamos que a câmera, apesar de já ser uma tecnologia muito comum atualmente, ainda é um fator que faz muitas pessoas agirem de modo não natural quando estão diante de uma lente, dependendo da personalidade de cada pessoa. Talvez a lente amplie características que as pessoas possuem no dia a dia: por exemplo, uma pessoa tímida pessoalmente pode ficar ainda mais tímida em frente à câmera, mesmo que a pessoa que está por trás da lente seja íntima.

\section{Filmes de família como objeto de estudo}

Os filmes domésticos ou de família têm recebido atenção de pesquisadores em diversos países como Espanha, Estados Unidos, França e Itália. No Brasil, a temática começa a se tornar relevante no ambiente acadêmico a partir de 2010, com as dissertações de mestrado: Filmes domésticos: uma abordagem a partir do acervo da Cinemateca Brasileira, de Lila Silva Foster (Universidade Federal de São Carlos), e Vídeos de família: entre os baús do passado e as telas do presente, de Lígia Azevedo Diogo (Universidade Federal Fluminense).

Entre as autoras citadas e outros pesquisadores, pudemos observar o estudo das temáticas de: patrimonialização de filmes de família e disponibilização destes em acervos públicos; reapropriação e recontextualização de filmes amadores no documentário contemporâneo; disponibilização de vídeos domésticos na internet; a comparação de filmes e vídeos de família feitos antes e depois da popularização da internet e das câmeras digitais. Cada abordagem, a seu modo, dá um caráter diferenciado a esses documentos, no qual a exibição de memórias familiares não é mais restrita ao ambiente privado: trata-se da publicização da vida particular das famílias (em acervos públicos, documentários, ou na internet).

Entretanto, não foram encontradas, até agora, no Brasil, dissertações que tratem especificamente a questão estética dos filmes domésticos, no sentido de pensar o que é narrado, quem são os personagens, e que efeitos causam no espectador. O pesquisador francês Roger Odin (2010), referência nos estudos sobre filmes domésticos, os define da seguinte forma:

Por cinema doméstico entendo um filme (ou um vídeo) realizado por um membro de uma família a propósito dos personagens, acontecimentos ou 
objetos ligados de uma ou outra maneira à história dessa família, e de uso preferencial pelos membros dessa mesma família. (ODIN, 2010, p.39) 4

Esses filmes possuem uma linguagem peculiar, destrinchada em diversos textos. De acordo com o autor (2010), os filmes de família são como fotografias animadas (pessoas posam ante um monumento ou paisagem), não possuem encerramento (como se fossem fragmentos de textos), são dispersos narrativamente (os filmes de família não contam uma história linear), apresentam saltos (são ignorados os processos que dão coerência aos planos), revelam olhares para a câmera (interação com a pessoa por trás da câmera), apresentam uma temporalidade indeterminada (ordem cronológica primária - não há flashbacks, por exemplo), constroem uma relação paradoxal com o espaço (os planos apenas dizem por quais lugares aquelas pessoas estiveram) e produzem interferências na percepção (imagens tremidas, borradas, arranhadas).

Em nosso trabalho de graduação, no qual estudamos filmes de família, descrevemos seis características das películas. São elas: 1) Felicidade - a maioria dos filmes domésticos mostram momentos felizes, de tranquilidade e paz, longe das questões preocupantes ou que causam tristeza, como os dilemas existenciais, o trabalho, a morte, as brigas entre integrantes da família; 2) Narrativa não-linear - os filmes caseiros, geralmente, registram acontecimentos sem uma narrativa completa, ou seja, não são compostas de início, meio e fim notadamente definidos; 3) Ausência de técnica - Imagens fora de foco, com enquadramento ruim, tremidas, muito escuras ou claras demais, um dedo intrometido na lente da câmera, som de palavras incompreensíveis, barulho de vento; 4) Cineasta participante - o cineasta de família quer registrar os momentos da família, porém, sem preocupação com a técnica ou com o resultado final do trabalho - acenos, sorrisos e olhares podem, ou devem, ser direcionados para a câmera; 5) Função de ressignificação - o que importa é a exibição dos filmes; assisti-los depois de prontos, mesmo que as imagens por si só não façam sentido, pois, na projeção, elas são ressignificadas pelos membros da família; 6)

\footnotetext{
4 Tradução nossa de: "Por cine doméstico entiendo una película (o un vídeo) realizados por un miembro de una familia a propósito de personajes, acontecimientos u objetos ligados de una u otra manera a la historia de esa familia, y de uso preferente por los miembros de esa misma familia”.
} 
Documento histórico - os filmes domésticos feitos principalmente entre membros de uma família registram o cotidiano, mostrando quais as tecnologias usadas em determinada época, como se deu a urbanização de tal cidade, quais eram as roupas e hábitos frequentes em um grupo social.

Já na dissertação de mestrado, vamos continuar a pesquisa, mas enfocando três eixos: 1) o diretor, geralmente o pai de família, pessoa que maneja a câmera e elege o que vai registrar; 2) os personagens que aparecem diante das câmeras e 3) o espectador, que normalmente é um dos personagens do filme, mas também pode ser uma pessoa de fora do grupo familiar interessada nesses registros (um diretor de filmes documentais ou ficcionais que queira utilizar filmes de arquivos privados, um pesquisador acadêmico, etc.).

Para nos aprofundarmos no tema, utilizaremos filmes domésticos como objeto de estudo. Como objeto empírico de análise, selecionaremos filmes domésticos feitos por famílias de Juiz de Fora na bitola Super 8, filmados durante a década de 1970, período em que essa película foi mais utilizada no Brasil. Nessa época, as câmeras fotográficas eram mais acessíveis do que as cinematográficas e o Super 8 se tornou a primeira tentativa de popularizar o registro de imagem em movimento, ainda que se mantivesse restrito a famílias de classe média alta.

Devido a pesquisas anteriores (trabalho de conclusão de curso e busca por acervos particulares), até o momento temos acesso a cerca de 20 rolos de película de oito famílias diferentes, somando mais de três horas e meia de materiais para o estudo. Pretendemos trabalhar com acervos privados de famílias que possuam mais de um rolo de filme, para que nossa análise não se estenda além do necessário. Para estudar as películas, utilizaremos categorias de análise fílmica aplicada ao estudo de produtos audiovisuais.

No momento, nossa pesquisa está na etapa de busca de referências bibliográficas que abordem memória, direção cinematográfica, escrita de si (em palavras ou imagens) e a espectatorialidade em filmes de família, além de um leitura flutuante do material já adquirido.

Enquanto temos uma breve leitura flutuante, podemos dizer que, nos filmes de família em Super 8, são registrados eventos como batizados, festas de natal, 
aniversários, bodas, casamentos, formaturas, carnaval, recepções a alguém da família. Mas, na maioria das imagens, são registrados apenas momentos de lazer entre a família, não somente de celebrações, como passeios na praia, no zoológico, no parque ou numa cachoeira, viagens, brincadeiras de crianças, um casal namorando. Algumas vezes, os cinegrafistas filmam programas na televisão: jogos de futebol, filmes de faroeste.

Geralmente a câmera se interessa em registrar as brincadeiras das crianças, aniversários infantis, passeios e viagens, como a própria bibliografia especializada no assunto nos mostra. Por vezes, os adultos mostrados agem com naturalidade, como se não houvesse uma câmera ali; em outros casos, as pessoas permanecem imóveis, como se não quisessem aparecer muito diante da lente; em algumas cenas, quando os adultos olham diretamente para a câmera, se mostram embaraçados; já em outras, os adultos se mostram à vontade com a câmera. As crianças com certa idade (a partir dos 3 ou 4 anos de idade) geralmente enxergam a câmera de forma lúdica, portandose como se aquele artefato fosse parte de uma brincadeira.

Quanto à recepção dos filmes de família e o efeito provocado por estes, pudemos ter acesso a comentários sobre a recepção aos filmes produzidos na década de 1970, em nosso trabalho de monografia (SANTOS,2014), de integrantes da família que estiveram presentes nas cenas, de alguns que não estiveram e do realizador dos filmes. Os filmes foram digitalizados, hospedados no YouTube e disponibilizados em um grupo familiar do realizador dos filmes, denominado "Primaiada". Por meio dos comentários, podemos observar as diversas emoções acarretadas por aquelas imagens: a alegria de rever pessoas amadas; um saudosismo pelos momentos mostrados, sempre tão felizes; a gratidão por aqueles momentos terem sido registrados e se tornado acessíveis a todos; a expectativa de assistir a mais filmes como aqueles; os sentimentos aconchegantes que as imagens trouxeram de paz, calor e beleza; flashes de outras lembranças, não mostradas nos filmes; alegria de poder assistir a um evento no qual não esteve presente.

Quando se trata da recepção à época original dos filmes, poucas semanas ou meses depois de terem sido feitos, acreditamos que havia uma espécie de celebração quando se uniam primos e irmãos (geralmente crianças) para assistir aos filmes de 
família. Encontramos no blog do jornalista Gustavo Junqueira 5 um texto que ilustra o imaginário das crianças cujos pais fizeram filmes de família em Super 8 na década de 1970 .

Há 35 anos, voltávamos de férias e aguardávamos ansiosos os dias até meu pai revelar os filmes - um, no máximo dois ou três, cada qual com três minutos de duração. À noite, eu e meus irmãos nos juntávamos na sala de estar escura em Belo Horizonte enquanto o projetor era montado e o rolo ajeitado para exibição na parede. Tratava-se de uma legítima sessão de cinema mudo, um alvoroço danado cada vez em que aparecíamos ali na nossa sétima arte particular. Para aumentar as emoções, meu pai congelava algumas imagens, ou colocava em slow motion, e nós gritávamos, dávamos risadas, fazíamos gozações com a performance alheia.

Depois da sessão, já era hora de dormir, minha mãe nos levava para a cama e debaixo dos lençóis eu adormecia pensando no filme que passara e quando seriam as próximas férias, os próximos filmes. (JUNQUEIRA, 2011)

Podemos observar como o cinema povoava o imaginário de crianças e adultos da época, porém a bitola cinematográfica de $35 \mathrm{~mm}$ muito cara era usada por profissionais e o Super 8, como película amadora de relativo baixo custo, proporcionava essa experiência de "sétima arte particular" citada no texto. Uma sessão de cinema em que os integrantes da família apareciam na tela divertia os personagens e também espectadores.

Já para pessoas de fora da família e que não participaram daqueles filmes, acreditamos que não há, necessariamente, um sentimento de saudosismo. A pesquisadora Sara Martín Rojo (2012), em seu trabalho "A hibridação de gêneros em Trem de sombras", investiga um filme em que são utilizadas imagens pretensamente familiares. Rojo defende que a estratégia do autor, o cineasta Jose Luís Guerín, em utilizar essas imagens, é de nos fazer crer na história do filme.

Confiamos "cegamente" nas imagens que vemos só pelo fato de não sermos os destinatários. Este tipo de material se apropria de nossos sentimentos familiares. Conseguimos facilmente identificar-nos com essa família desconhecida, pois todos dispomos deste tipo de referentes. (ROJO, 2012, p.293)

5 JUNQUEIRA, Gustavo. Os anos 70 sob a ótica do Super 8. Disponível em: <http://www.revide.com.br/blog/gustavo-junqueira/os-anos-70-sob-otica-do-super-8/>. Acesso em: 07 jul. 2015. 
Ou seja, podemos inferir que imagens domésticas passam uma autenticidade, de que aquelas cenas possuem um referente no tempo e no espaço, a crença de que as pessoas que ali aparecem são pessoas reais, inscritas em um grupo familiar como o nosso. Existe uma identificação com os personagens na tela, mas talvez as cenas não nos transportem, na mesma hora, a outras épocas.

\section{Considerações}

Exibir aquilo que define nossa identidade pessoal. Esse é o ponto que defendemos como principal objetivo das autorrepresentações encontradas em álbuns físicos, filmes e vídeos de família e, especialmente, as que exibimos nas redes sociais para nossos amigos e colegas. A identidade está inteiramente ligada à imagem; é o que faz cada indivíduo ser único, diferente em meio à multidão. A busca por uma imagem adequada é o que nos faz agir de tal ou tal forma diante e mesmo por trás das câmeras.

Podemos dizer a auto-mise en scène de cada pessoa é menos afetada pela antiga "celebrização" dos momentos vividos em família que desejamos documentar, pois muitos desses registros são feitos em situações rotineiras, geralmente sem grande relevância. Mas a câmera fotográfica ou de vídeo, apesar de já se tratar de um equipamento muito utilizado atualmente, ainda faz cada um agir de modo não natural, dependendo de fatores como a personalidade tímida ou extrovertida de uma pessoa.

Existe, atualmente, certa necessidade em registrar momentos fugazes. As redes sociais, nossos álbuns particulares, são compostos por fotos e vídeos que queremos mostrar para passar certo tipo de imagem, a imagem que queremos que o outro tenha de nós. Nossa hipótese é de que a intimidade familiar é extremamente guiada pela identidade pessoal e pelo habitus social que representamos, para que outras pessoas nos reconheçam.

Por meio de leitura flutuante do material já recolhido, podemos pensar nos filmes de família como objeto de memória, no qual a intimidade de um grupo familiar se encontra representada por meio de gestos e ações. Também acreditamos que as crianças são, talvez, os personagens mais importantes dos filmes domésticos - são 
elas as personagens que mais aparecem nas imagens e as mais pareciam se divertir com as exibições em família.

\section{Referências}

ARTIÈRES, Philippe. Arquivar a própria vida. Estudos históricos, vol.11, $\mathrm{n}^{0}$ 21, Rio de Janeiro: FGV, 1998. Disponível em: < http://bibliotecadigital.fgv.br/ojs/index.php/reh/article/view/2061/1200>. Acesso em: 09 set. 2015.

BAZIN, André. Ontologia da imagem fotográfica. In: BAZIN, André. O Cinema (ensaios). São Paulo: Brasiliense, 1991. Disponível em: < https://cineartesantoamaro.files.wordpress.com/2011/o5/o-cinema-ensaiosandre-bazin.pdf $>$. Acesso em: 09 set. 2015.

CARUSO, Carlos Alberto Antonio. O filme de família: O Fascínio da Preservação da Imagem, Histórias e Memórias. 2012. Dissertação (Mestrado em Comunicação) - Universidade Anhembi Morumbi, São Paulo, 2012. Disponível em: $\quad<\quad$ http://portal.anhembi.br/wpcontent/uploads/Dissertacao_Carlos_Alberto_Antonio_Caruso1.pdf $>$. Acesso em: 09 set. 2015.

COMOLLI, Jean-Louis. Carta de Marselha sobre a auto-mise en scène. In: Forumdoc.bh.2001. Publicação do $5^{0}$ Festival do Filme documentário e etnográfico, fórum de antropologia, cinema e vídeo. Belo Horizonte, 9 a 18 nov. 2001.

DIOGO, Lígia Azevedo; FURLONI, Álvaro Fernandez. Cadê o passarinho? A ameaça de extinção da pose na imagem de família. Contemporânea, vol.7, $\mathrm{n}^{0} 1,2009$. Disponível em: http://www.contemporanea.uerj.br/pdf/ed_12/contemporanea_n12_02_ligia_ alvaro.pdf $>$. Acesso em: 09 set. 2015.

DIOGO, Lígia Azevedo. Vídeos de família: entre os baús do passado e as telas do presente. 2010. Dissertação (Mestrado em Comunicação) - Universidade Federal Fluminense, Niterói, 2010. Disponível em: < http://www.bdtd.ndc.uff.br/tde_busca/arquivo.php?codArquivo=4055>. Acesso em: 09 set. 2015.

FOSTER, Lila Silva. Filmes domésticos: uma abordagem a partir do acervo da Cinemateca Brasileira. Dissertação (Mestrado em Imagem e Som) Universidade Federal de São Carlos, São Carlos, 2010. Disponível em: < http://www.bdtd.ufscar.br/htdocs/tedeSimplificado/tde_busca/arquivo.php?co dArquivo=2965 $>$. Acesso em: 09 set. 2015.

GONDAR, Jô.. In: Memória e espaço. Rio de Janeiro: 7Letras, 2000. Lembrar e esquecer: desejo de memória, p. 35-43.

HUYSSEN, Andreas. Seduzidos pela memória: arquitetura, monumentos, mídia. 2. ed. Rio de Janeiro: Aeroplano, 2004. 
MUSSE, Christina Ferraz; MUSSE, Mariana Ferraz. Memórias ressignificadas: as narrativas de super 8 na web 2.0. In: ENCONTRO REGIONAL SUDESTE DE HISTÓRIA DA MÍDIA. 3., 2014, Rio de Janeiro. Anais... Rio de Janeiro: Alcar, 2014.

ODIN, ROGER. El cine doméstico en la institución familiar. In: ÁLVAREZ, Efrén Cuevas (ed.). La casa abierta: el cine doméstico y sus reciclajes contemporáneos. Ayuntamiento de Madrid, 2010. p. 39-60.

ROJO, Sara Martín. A hibridação de gêneros em Trem de sombras. In: Josette Monzani, Luciana Corrêa de Araújo, Susana Reck Miranda.. ... [et al]. Estudos de Cinema e Audiovisual Socine: estadual São Paulo. São Paulo: Socine, 2012. em: http://www.socine.org.br/livro/socine_sp.pdf >. Acesso em: o9 set. 2015.

SANTOS, Ana Clara Campos dos. Memória e filmes domésticos em Super 8: a família Assis em Juiz de Fora - MG. Monografia (Bacharel em Comunicação Social). Universidade Federal de Juiz de Fora, Juiz de Fora, 2014. Disponível em: $<$ https://pesquisafacomufjf.files.wordpress.com/2013/o6/memc3b3ria-efilmes-domczagsticos-em-super-8-a-famczadlia-assis-em-juiz-de-fora-mg.pdf $>$. Acesso em: 09 set. 2015.

SILVA, Armando. Álbum de família: a imagem de nós mesmos. São Paulo: Senac, 2008. 